\title{
The Impact of Semantic Clustering on the Learning of Abstract Words
}

\author{
Tomoko Ishii \\ Meiji Gakuin University \\ doi: http://dx.doi.org/10.7820/vli.v06.1.Ishii
}

\begin{abstract}
It has been repeatedly argued among vocabulary researchers that semantically related words should not be taught simultaneously because they might interfere with each other. However, the types of relatedness that cause interference have rarely been examined carefully. In addition, past studies that have examined this issue disagree, with some providing results showing that semantic clustering does not cause interference and confusion. Reviewing the literature on working memory, a previous paper by the author indicated that psychologists have long seen visual stimulus as an important component of information processing. Researchers of vocabulary learning have also witnessed some evidence that learners do resort to visual imagery when trying to remember new words. Based on such psychological and applied linguistic research, previous research by the author revealed that visually related items may cause confusion despite the lack of semantic connection. Conversely, visually controlled, semantically related items do not seem to cause confusion. This paper presents the follow-up study, examining the learning of semantically related abstract words that do not have concrete visual images. No evidence to indicate any confusion in the learning of such items was obtained. This supports the working hypothesis that the impeding effect of semantic clustering repeatedly reported in the past could partly be due to the shared visual features of semantically similar words.
\end{abstract}

Keywords: vocabulary, semantic clustering, interference, abstract words, visual imagery.

\section{Introduction}

The advancement of research in second-language vocabulary acquisition has led to many approaches and beliefs about how words should be taught. Among those is the view that semantically related words should not be introduced together. When the new words that are introduced simultaneously overlap semantically, they are believed to interfere with each other and impede learning (Nation, 2013).

Research on such interferences developed in the context of memory research, and experiments were conducted using the first language of the participants. With a wide range of review of the literature addressing this issue, Waring (1997) cited McGeoch and McDonald (1931), who argued that meaningful relationships among the items to be learned interfere with learning. Higa (1963) also showed that certain types of semantic relationship can have a negative influence 
on learning. These studies, along with others, led psychologists to develop the "Interference Theory" (Crowder, 1976, cited in Tinkham, 1993), which states that people have more difficulty while learning items that share many common elements, than while learning dissimilar items.

Tinkham (1993) applied this theory in the context of second-language learning, having his participants learn words in their first language paired with a pseudoword, modeling the condition where learners of a foreign language attempt to remember the meaning of new words. He compared the efficacy of learning words from two different sets: semantically related and unrelated. In the former, the words were grouped under a semantic category such as "fruits" (apple, orange, and pear), whereas in the latter, the words were unrelated. Displaying the participants' need for a greater number of repetitions to learn the former, Tinkham (1993) argued that "Interference Theory" is applicable to second-language vocabulary learning as well.

The concept that students should not learn semantically related items simultaneously actually contradicts the intuition of many teachers and learners. Perhaps this contradiction is the reason why this subject has attracted attention. With further empirical studies supporting this concept (Tinkham, 1997; Waring, 1997), the negative influence of semantic clustering on vocabulary learning came to be widely recognized. In his book examining various teacher and learner beliefs about vocabulary learning, Folse (2004) lists "Presenting new vocabulary in semantic sets facilitates learning" as one of seven vocabulary learning myths. Labeling this statement a myth suggests that numerous people believe that grouping words semantically will improve learning efficacy, although it appears to be false. Ishii and Maruyama (2009) conducted a survey with Japanese university students to discover if learners believe this statement or not. The survey revealed that $64 \%$ of the 543 participants believed this idea, 12\% disagreed, with $24 \%$ being unsure. These results suggested that learners generally accept the statement that semantically grouped words are easier to learn; a majority of them expressed their belief in it, with only a small percentage of them explicitly disagreeing with it. It therefore supports that many learners agree with the statement that presenting new vocabulary in semantic sets facilitates learning.

However, regarding the veracity of this statement, as was discussed by Ishii (2015), research in this line has not reached a consensus. Some studies observed the negative effect only among a segment of their participants (Papathanasiou, 2009), while others, particularly those conducted in classrooms rather than laboratories, revealed a positive impact of semantic clustering on learning vocabulary items (Hashemi \& Gowdasiaei, 2005; Hoshino, 2010). As Nation and Webb (2011) emphasize, research in this field has not been investigated thoroughly enough in the actual teaching context. Early studies on this issue, both in L1 and L2 contexts, were predominantly conducted under significant time pressure, without providing the participants adequate time to explore their own learning strategies. As such, we have little information about how semantic clustering affects learning in genuine learning conditions. It is therefore particularly informative that some classroom-based studies have displayed different results from previous laboratory-based ones.

Given the diverse results about the impact of semantic clustering on learning words, Ishii (2015) urges the necessity for a detailed examination of the sources 
of the confusion between semantically related words. Reviewing the literature on memory studies, the paper indicated that psychologists have long seen visual stimulus as an important component of information processing, offering a new perspective on the issue of semantic clustering. Baddeley and Hitch (1974) proposed a model of working memory, a system that information first goes through when people process it, which included two initial components: the "phonological loop" - processing sound, and the "visuo-spatial sketchpad" - handling visual images. Though multiple revisions of working memory have been proposed over the years, they have always included a visual component (e.g., Baddeley, 2000; Logie, 1995). This consistent inclusion of a visual component suggests that psychologists attribute special importance to visual information when explaining the nature of human memory.

In addition to the literature review on memory studies, Ishii (2015) examined the research materials used in the previous studies on semantic clustering, and revealed a significant overlap in shape among the referents of the words the participants were expected to learn. For instance, "fruit" was a common semantic category employed in the literature, and many of the fruits selected for the studies were round (e.g., orange, apple, and peach). Similarly, a significant majority of "animals" were four-legged (e.g., dog, cat, and lion), while "clothes" such as jacket, shirt, and coat also shared some physical features. Of course, being grouped under a semantic category does not necessarily yield physical commonality among the referents; however, a review of the literature revealed that several semantically grouped items shared common features like shape (see Table 1). For instance, in addition to the examples of fruits and clothes mentioned above, we discerned similarities in shape among kitchen utensils (e.g., spoon, fork, and knife) and furniture (e.g., chair, couch, and desk or table). Tinkham (1997) exhibited the most extreme case, using metal names (tin, bronze, iron, etc.), which are visually challenging to distinguish. Given such shared visual features, as well as the importance attributed to visual information in psychology literature, Ishii (2015) adopted a working hypothesis that the alleged impeding effect of semantic clustering was partly due to the shared characteristics of shapes among the referents of semantically grouped words.

Based on this hypothesis, Ishii (2015) investigated whether a negative impact of semantic clustering was observed when the clustered words were controlled so that their referents had a limited shared visual connection. A second aim of the study was to determine if a semantically unrelated word set, whose referents shared a visual feature (e.g., round objects such as globe, watermelon, and ball), had a negative influence on the learning of those words. To answer these two questions, the study compared the learning of (1) unrelated, (2) semantically related (but physically dissimilar), and (3) physically related (but semantically un related) sets of words. It was reported that, both on the immediate and the delayed posttests, physically related sets yielded lower average scores than the other two sets, and the difference was confirmed to be statistically significant. In contrast, the test scores from semantically related sets were not significantly different from the unrelated sets.

These findings support the hypothesis that the apparent impeding effect of semantic clustering stems from the shared physical features of the referents in 
Table 1. Words Employed in Certain Earlier Studies on the Subject of Semantic Clustering

\begin{tabular}{|c|c|c|c|}
\hline Researchers & $\begin{array}{l}\text { Conclusion about } \\
\text { semantic clustering }\end{array}$ & $\begin{array}{l}\text { Semantic } \\
\text { categories }\end{array}$ & $\begin{array}{l}\text { Words used in } \\
\text { the experiment }\end{array}$ \\
\hline Tinkham (1993) & Negative & $\begin{array}{l}\text { Clothes } \\
\text { Fruits }\end{array}$ & $\begin{array}{l}\text { Shirt, jacket, sweater } \\
\text { Pear, apple, apricot, plum, } \\
\text { peach, nectarine }\end{array}$ \\
\hline Tinkham (1997) & Negative & $\begin{array}{l}\text { Kitchen utensils } \\
\text { Metal }\end{array}$ & $\begin{array}{l}\text { Dish, bowl, plate } \\
\text { Tin, bronze, iron, brass, lead, } \\
\text { steel }\end{array}$ \\
\hline Waring (1997) & Negative & Fruits & $\begin{array}{l}\text { Melon, apple, strawberry, } \\
\text { grape, peach, orange }\end{array}$ \\
\hline $\begin{array}{l}\text { Finkbeiner } \\
\text { and Nicol (2003) }\end{array}$ & Negative & $\begin{array}{l}\text { Animals } \\
\text { Kitchen utensils } \\
\text { Furniture } \\
\text { Body parts }\end{array}$ & $\begin{array}{l}\text { Cat, cow, dog, elephant, } \\
\text { horse, lion, pig, tiger } \\
\text { Bowl, cup, fork, frying pan, } \\
\text { knife, pot, spoon, stove } \\
\text { Bed, chair, couch, } \\
\text { desk, dresser, lamp, } \\
\text { table, television } \\
\text { Ear, eye, foot, hair, hand, leg, } \\
\text { nose, toe }\end{array}$ \\
\hline $\begin{array}{l}\text { Erten and } \\
\text { Tekin (2008) }\end{array}$ & Negative & $\begin{array}{l}\text { Animals } \\
\text { Foods }\end{array}$ & $\begin{array}{l}\text { Bat, bee, pig, fox, hen, ape, } \\
\text { ant, cow, owl, cock, crab, } \\
\text { wolf, seal, bear, goat, sheep, } \\
\text { eagle, snake, shark, snail } \\
\text { Egg, fig, leek, plum, bean, } \\
\text { pear, salt, okra, corn, onion, } \\
\text { olive, melon, honey, grape, } \\
\text { garlic, pepper, carrot, radish, } \\
\text { cherry, peanut }\end{array}$ \\
\hline $\begin{array}{l}\text { Papathanasiou } \\
\text { (2009) }\end{array}$ & $\begin{array}{l}\text { Negative among adult } \\
\text { beginners, and no } \\
\text { difference among } \\
\text { intermediate children }\end{array}$ & $\begin{array}{l}\text { Crime } \\
\text { Nature } \\
\text { Food } \\
\text { Synonyms (pairs) } \\
\text { Antonyms (pairs) }\end{array}$ & $\begin{array}{l}\text { Smuggling, terrorism, } \\
\text { forgery, mugging, trial, } \\
\text { proof, jury, verdict, } \\
\text { witness, bribery } \\
\text { Cape, peninsula, cave, } \\
\text { tributary, valley, gorge, } \\
\text { stream, estuary, ridge, } \\
\text { summit } \\
\text { Lamb, herring, veal, ham, } \\
\text { cod, trout, prawn, shrimp, } \\
\text { squid, lobster } \\
\text { Torment, torture/jab, punch/ } \\
\text { spat, quarrel/gleam, twinkle/ } \\
\text { boredom, tedium } \\
\text { Ebb, flow/gloom, glee/ } \\
\text { certitude, doubt/loyalty, } \\
\text { treason/ poverty, prosperity }\end{array}$ \\
\hline Hoshino (2010) & Positive & $\begin{array}{l}\text { Various word } \\
\text { pairs }\end{array}$ & $\begin{array}{l}\text { Moth, wasp/asthma, } \\
\text { diabetes/calf, } \\
\text { chick/borough, province/ } \\
\text { solicitor, astronomer }\end{array}$ \\
\hline $\begin{array}{l}\text { Hashemi and } \\
\text { Gowdasiaei (2005) }\end{array}$ & Positive & $\begin{array}{l}\text { Materials not } \\
\text { disclosed }\end{array}$ & \\
\hline
\end{tabular}

Note: Some of these studies included categories that were not related to semantic connections (e.g., homonyms in Papathanasiou [2009]). Such categories are not listed in this table. 
semantically grouped words. A question then naturally emerges - if the source of confusion lies in the visual image of the referents, what happens when no distinct visual image is available? More specifically, what is the impact of semantic clustering in the case of the words without a tangible visible referent? This study was designed to address this question in order to further examine Ishii's (2015) hypothesis.

The following sections of this paper will first discuss the role of visual imagery in the learning of vocabulary items in a second language to provide additional background to the hypothesis. It will then describe the method undertaken to compare the learning efficacy of (1) unrelated and (2) semantically related sets of abstract words, followed by the results of the experiment.

\subsection{Role of visual imagery in learning words}

In addition to the memory models mentioned above, other psychological studies have also attributed an importance to human memory. For instance, Paivio (1969) proposed the "Dual Coding theory" that argues for the important role visual imagery plays in human memory. According to this theory, we elaborate our learning through the creation of visual images and verbal associations. After several decades, this theory still serves as a basis for the understanding of human cognition (Paivio, 2013). The theory suggests that learning outcomes are better when people successfully create visual images in their minds, as well as when they think about their meanings and create associative networks around them.

In line with this theory, the use of visual imagery has long been supported as a useful mnemonic technique (Nation, 1990). Second-language vocabulary researchers have also witnessed learners resorting to visual imagery when trying to remember new words, of which some examples are provided later.

In his study investigating incidental vocabulary learning through reading, Yoshii (2006) examined the gain in the meaning retrieval with four different glosses: L1 text only, L2 text only, L1 plus picture, and L2 plus picture. As a result, while no difference in vocabulary gain was observed between L1 and L2 text only glosses, the addition of pictures to the glosses contributed significantly to the incidental learning of vocabulary through reading. This suggests that the use of pictures assists the students in forming visual mental representations that facilitate the retention of the word meaning.

Boers, Lindstromberg, Littlemore, Stengers, and Eyckmans (2008) and Boers, Piquer Píriz, Stengers, and Eyckmans (2009) investigated the effect of pictorial elucidation when learning new idiomatic expressions. The studies revealed that learners retain the meanings of newly learned idiomatic items better when they are presented with visual images. Though there was no impact for the word forms, such presentations at least improved the learning of word meanings.

Farley et al. (2012) examined if the meaning recall of words improved in the presence of imagery, and found that only the meaning recall of abstract words improved, while that of concrete nouns did not. A possible interpretation of this finding is that, in the case of concrete nouns, most learners can naturally produce visual images in their mind and use them to remember the words. Therefore, the 
additional visual images in the learning material do not affect the learning outcome, since they are already present in their mind. However, in the case of abstract nouns, since it is often difficult for learners to create images independently, the presentation of imagery helps them retain the meaning of the words they are trying to learn.

All these studies, though they focus on different issues, suggest that second-language learners use visual imagery when trying to remember new lexical items. Studies on semantic clustering typically ask the participants to learn new lexical items, and we can expect the learners under such experimental conditions to resort to visual imagery. It is therefore reasonable to assume that the overlap in the shape of the referents of the target words makes it more difficult for the learners to commit the words to memory, as such words lead to similar visual imagery the learners create in their mind.

Investigations into the learning of semantically grouped words most frequently have been conducted using nouns referring to concrete objects, though some studies have included abstract nouns (Papathanasiou, 2009). However, to the best of my knowledge, no study has specifically investigated the influence of semantic clustering while learning abstract nouns that do not have a tangible object as their referents. The current study was designed to examine this issue, and was conducted under the following hypothesis and research question.

Hypothesis:

The apparent negative effect of semantic grouping is partly due to the shared features of the shape of the referents.

Research question:

Is the efficacy of learning of word meaning influenced by grouping abstract nouns into semantic sets?

Based on the hypothesis above, it was predicted that grouping abstract words into semantic sets would not influence the efficacy of learning negatively, as abstract words do not have a referent with a concrete shape. The hypothesis, however, does not allow us to predict whether such clustering has a positive influence on learning. The following sections of this paper will describe the investigation of this hypothesis and will present the results.

\section{Method}

This study was conducted with 62 Japanese university students, who were first-year Economics majors. The purpose of the study - to contribute to the understanding of how people learn vocabulary - was explained to the participants. They were also aware that they would be learning pairs of Japanese meanings and nonwords. However, no further details about the grouping of the words were disclosed until the completion of the experiment. During the experiment, the participants learned pseudowords paired with meanings (a word given in their native language, Japanese), under two categories: "unrelated" and "semantically related." The former category grouped five abstract words that had no obvious semantic relationships, whereas the latter was a collection of five abstract words grouped under 
the following concepts: personality traits, feelings, talking, and crime. The English translations of the Japanese words used in the experiment are displayed in Table 2.

Each category contained four sets of five pairs of pseudowords and Japanese words, namely, 20 pairs in each category, totaling 40 pairs that needed to be learned. All the participants learned the words in both categories, and the difference in performance in both categories was compared within subject.

The pseudowords used in this experiment were generated using a computer program called Wuggy (Keuleers \& Brysbaert, 2010) that produces pseudowords conforming to English spelling rules. As the software produced pseudowords in accordance with the number of syllables as well as vowel-consonant combinations of the English words entered, it allowed us to control the length and phonological pattern of the pseudowords used in the experiment. The materials were prepared such that the pseudowords included in both categories were balanced in terms of the number of syllables and letters. In addition, in order to account for the possibility that one set of pseudowords might be easier to learn, the pairings were varied.

The participants were asked to memorize one set of five pairs, displayed on a screen, in 40 seconds. This time limit was determined based on the results of a pilot study conducted with three students with a similar background to the participants of this study. Immediately following the 40 -second learning session, the participants took a meaning recall test where they demonstrated their memory of the meanings represented by the pseudowords (Test 1). Repeating this learning and testing cycle eight times, they were exposed to all 40 pairs of pseudowords and meanings. They then spent 20 minutes on a class activity that was not part of this experiment, and took another test (Test 2) without any prior notification. Test 2 presented all the 40 pseudowords alphabetically, and the participants were asked to write down the meaning associated with each.

\section{Results}

Tables 3 and 4 present the results of the two tests in the study. In Test 1, in both the categories, the average score was about $60 \%$ (Table 3 ). However, the score

Table 2. Japanese Meanings Employed in the Study

\begin{tabular}{|c|c|c|}
\hline Category & Nature of the connection & Meaning represented in Japanese \\
\hline Unrelated & $\begin{array}{l}\text { There is no obvious connection } \\
\text { among the words }\end{array}$ & $\begin{array}{l}\text { (1) Difference, summary, speed, concern, view } \\
\text { (2) Power, play, remaining, help, attention } \\
\text { (3) Cause, patience, situation, grammar, } \\
\text { determination } \\
\text { (4) Memory, variety, completion, role, question }\end{array}$ \\
\hline Semantic & $\begin{array}{l}\text { Words (meanings represented in } \\
\text { Japanese) are categorized under } \\
\text { the following themes: (1) personality } \\
\text { traits, (2) feelings, (3) talking, } \\
\text { (4) crime }\end{array}$ & $\begin{array}{l}\text { (1) Kindness, brightness, honest, bravery, } \\
\text { intelligence } \\
\text { (2) Happiness, sadness, anger, surprise, } \\
\text { worried } \\
\text { (3) Conversation, negotiation, instruction, } \\
\text { suggestion, agreement } \\
\text { (4) Statement, guilt, testimony, arrest, release }\end{array}$ \\
\hline
\end{tabular}


Table 3. Results from Test $1(N=62$, Possible $\max =20)$

\begin{tabular}{lccccc}
\hline & Max & Min & Mean & SD & SEM \\
\hline Unrelated & 20 & 3 & 13.00 & 4.53 & 0.58 \\
Semantic & 20 & 1 & 13.42 & 4.62 & 0.59 \\
\hline
\end{tabular}

Table 4. Results from Test $2(N=62$, Possible $\max =20)$

\begin{tabular}{lccccc}
\hline & Max & Min & Mean & SD & SEM \\
\hline Unrelated & 14 & 0 & 3.48 & 3.49 & 0.44 \\
Semantic & 13 & 0 & 3.85 & 3.31 & 0.42 \\
\hline
\end{tabular}

declined greatly after 20 minutes of distraction, which indicates poor retention of the learned meaning (Table 4).

As the tables show, the observed difference in the mean scores of the two categories was minor in both tests, and paired $t$-tests did not reveal a statistical significance for either of the tests $(t=1.15$ and $p=0.25$ for Test 1 , and $t=1.26$ and $p=0.21$ for Test 2).

\section{Discussion and conclusion}

The data presented above display no advantage or disadvantage of grouping abstract nouns into semantic categories. The current study was conducted under the hypothesis that the seemingly negative effect of semantic grouping is partly due to shared features in the shape of the referents. The results are consistent with this hypothesis, as the semantic grouping of abstract words, where the referent has no concrete shape, did not exhibit any impeding effect on the participants' memory. The semantic relatedness among the target words did not have a positive impact either.

However, the study presented in this paper has some limitations. First, since this was a laboratory-type research, and not a classroom embedded one, the participants had a tight time limitation to learn the words, and thus were unable to utilize their learning strategies. Second, it employed nonwords as the learning target. This was to avoid the risk of conflating the learning of target items with prior knowledge of the words. However, the disadvantage was that the participants did not perceive the value of memorizing these words, except to know that this study would contribute to knowledge about vocabulary instruction. If a similar study is conducted in a genuine classroom setting, where students learn words they perceive are important, with abundant time to review the target words, different results might be obtained. Third, the study only tested the meaning recall of the learned words. It is quite possible that the interrelationship between the target items have different effects on different sets of skills, such as receptive and productive knowledge. Therefore, it should be noted that investigating different types of knowledge might well provide a different result.

We should also be aware that there are learners with different cognitive styles. Boers et al. (2009) addressed this issue in their study of the influence of pictorial elucidation on the recollection of idioms. They argue that there are "high imagers" 
and "low imagers" who resort to mental imagery to different extents. Although they did not reach a solid conclusion, they suggest that pictorial presentation might influence high and low imagers in different ways. In the current study, the extent to which each participant resorted to mental imagery is unknown. Moreover, it is very likely that participants with different cognitive and learning styles perform differently, which is an interesting subject that can be addressed in a future study.

Although we need to be aware of these limitations, this study demonstrates how fragile the concept of the negative impact of semantic clustering is. Namely, it showed how the selection of words to be grouped semantically can greatly affect learning efficacy. In some earlier studies, the concept of "semantic clustering" has been discussed without defining what that meant. As Ishii (2015) previously argued, words can be connected semantically under different types of relationships and to different degrees. For example, under the category of "musical instruments," it is intuitively unlikely that the word cymbal is as closely located, in our mental lexicon, to the word piano as it probably is to the word organ. Thus, the term "semantic clustering" can refer to a variety of connections between words. However, the term has not been defined clearly enough to be considered an operational variable. In order for this line of research to reach a solid conclusion on this subject, future research needs to be designed with detailed consideration about the source and the process of the interference.

The current study, as well as my previous research, was conducted under the hypothesis that the shared features of the shape of the referents of the target words were a source of confusion. Namely, it proposes that some confusion emerges when learners resort to visual imagery while attempting to memorize the meaning of new words. The data obtained in the earlier study (Ishii, 2015) strongly support this hypothesis; also, the results presented in this paper are in accordance with this supposition. Further research, with insight about the cognitive processes of learners, conducted under a variety of conditions, and encompassing different types of knowledge, should reveal more about the nature of the relatedness among words that has an impact on the learning outcome.

\section{References}

Baddeley, A.D. (2000). The episodic buffer: A new component of working memory? Trends in Cognitive Sciences, 4(11), 417-423. doi:10.1016/ S1364-6613(00)01538-2

Baddeley, A.D., \& Hitch, G.J. (1974). Working memory. In G.A. Bower (Ed.), Recent advances in learning and motivation (Vol. 8, pp. 47-89). New York, NY: Academic Press.

Boers, F., Lindstromberg, S., Littlemore, J., Stengers, H., \& Eyckmans, J. (2008). Variables in the mnemonic effectiveness of pictorial elucidation. In F. Boers \& S. Lindstromberg (Eds.), Cognitive linguistic approaches to teaching vocabulary and phraseology (pp. 189-116). Berlin, Germany: Mouton de Gruyter.

Boers, F., Piquer Píriz, A., Stengers, H., \& Eyckmans, J. (2009). Does pictorial elucidation foster recollection of figurative idioms? Language Teaching Research, 13(4), 367-388. doi:10.1177/1362168809341505 
Crowder, R.G. (1976). Principles of learning and memory. Hillsdale, NJ: Lawrence Erlbaum.

Erten, I.H., \& Tekin, M. (2008). Effects on vocabulary acquisition of presenting new words in semantic sets versus semantically unrelated sets. System, 36(3), 407-422. doi:10.1016/j.system.2008.02.005

Farley, A.P., Ramonda, K., \& Liu, X. (2012). The concreteness effect and the bilingual lexicon: The impact of visual stimuli attachment on meaning recall of abstract L2 words. Language Teaching Research, 16(4), 449-466. doi: $10.1177 / 1362168812436910$

Finkbeiner, M., \& Nicol, J. (2003). Semantic category effects in second language word learning. Applied Psycholinguistics, 24, 369-383. doi:10.1017/ S0142716403000195

Folse, K.S. (2004). Vocabulary myths. Ann Arbor, MI: The University of Michigan Press.

Hashemi, M.R., \& Gowdasiaei, F. (2005). An attribute-treatment interaction study: Lexical-set versus semantically-unrelated vocabulary instruction. RELC Journal, 36(3), 341-361. doi:10.1177/0033688205060054

Higa, M. (1963). Interference effects of intralist word relationships in verbal learning. Journal of Verbal Learning and Verbal Behavior, 2(2), 170-175. doi:10.1016/S0022-5371(63)80082-1

Hoshino, Y. (2010). The categorical facilitation effects on L2 vocabulary learning in a classroom. RELC Journal, 41(3), 301-312. doi:10.1177/0033688210380558

Ishii, T. (2015). Semantic connection or visual connection: Investigating the real source of confusion. Language Teaching Research, 19(6), 712-722. doi:10.1177/1362168814559799

Ishii, T., \& Maruyama, Y. (2009). How mythical are 'Vocabulary Myths' among Japanese learners of English? The Journal of Rikkyo University Language Center, 21, 23-31.

Keuleers, E., \& Brysbaert, M. (2010). Wuggy: A multilingual pseudoword generator. Behavior Research Methods, 42(3), 627-633. doi:10.3758/BRM.42.3.627

Logie, R.H. (1995). Visuo-spatial working memory. Hove, UK: Laurence Erlbaum Associates.

McGeoch, A., \& McDonald, W.T. (1931) Meaningful relation and retroactive inhibition. American Journal of Psychology, 43(4), 579-588. doi:10.2307/1415159

Nation, I.S.P. (1990). Teaching and learning vocabulary. New York, NY: Newbury House.

Nation, I.S.P. (2013). Learning vocabulary in another language. Cambridge, UK: Cambridge University Press.

Nation, I.S.P., \& Webb, S. (2011). Researching and analyzing vocabulary. Boston, MA: Heinle Cengage Learning.

Paivio, A. (1969). Mental imagery in associative learning and memory. Psychological Review, 76(3), 241-263. doi:10.1037/h0027272

Vocabulary Learning and Instruction, 6 (1), 21-31. 
Paivio, A. (2013). Mind and its evolution: A dual coding theoretical approach. New York, NY: Psychology Press.

Papathanasiou, E. (2009). An investigation of two ways of presenting vocabulary. ELT Journal, 63(4), 313-322. doi:10.1093/elt/ccp014

Tinkham, T. (1993). The effect of semantic clustering on the learning of second language vocabulary. System, 21(3), 371-380. doi:10.1016/0346-251X(93)90027-E

Tinkham, T. (1997). The effects of semantic and thematic clustering on the learning of second language vocabulary. Second Language Research, 13(2), 138-163. doi:10.1191/026765897672376469

Waring, R. (1997). The negative effects of learning words in semantic sets: A replication. System, 25(2), 261-274. doi:10.1016/S0346-251X(97)00013-4

Yoshii, M. (2006). L1 and L2 glosses: Their effects on incidental vocabulary learning. Language Learning \& Technology, 10(3), 85-101. Retrieved from http:// llt.msu.edu/vol10num3/yoshii/ 